\title{
REPORTS
}

\author{
LUDWIK ZABROCKI
}

\section{The Institute of Applied Linguistics at the Adam Mickiewicz University, Poznań}

Before 1939 there were no special departments of the methodology of foreign language teaching at Polish universities. It was a domain of secondary school teachers. The problems of teaching foreign languages lay beyond university interests. The young grammarian linguistics did not help in the development of a scientific approach to these problems. Linguistics at that time was mostly occupied with historical-comparative studies. From all the branches of linguistics only young grammarian phonetics supplied some new data to the methods of teaching. Thus it were mainly phoneticians who dealt with the problems of teaching foreign languages. With this exception the so called grammatical-translation method was dominating. This method was borrowed from teaching classical languages; it is necessary to say that as far as teaching classical languages is concerned this method certainly had its advantages, but it was of no use in teaching modern languages. There were attempts to replace it by a direct method; Berlitz school of teaching foreign languaegs was founded on this method. It was not very much different from the way tutors (taught foreign languages. This method was based on large numbers theory, it did not take into account the economy of time. The structures of languages having not yet been worked out, it rightly chose the way of building matrices by the actual use of the language. The followers of this method did not, of course, know about the above mentioned theoretical foundations. In secondary schools the direct method had to fail since it did not pay any attention to time. Although the grammatical-translation method gave concrete results in the shape of knowledge about a language it did not, in any case, help to acquire fluency in speaking a foreign language.

Modern structural linguistics made a real revolution in the methodology of teaching foreign languages. Structuralism takes an interest in a synchronical state of a language in its structural and functional aspects. Working-out language structures and determining their functions brought new ideas into the methodology of teaching foreign languages. Harold E. Palmer was the first who tried to base the direct method on the premises of structural-functional linguistics (the term "structural" or "functional" only, with reference to modern linguistics, does not include all its essential features). He presented his ideas in his book On the Scientific Study and Teaching of Languages (1917). De Saussure's approach to language analysis also influenced the methods of teaching. The presentation of the subject of teaching alone, i.e. the presentation of a language as a system of structures as postulated by de Saussure determined to some degree the methods of teaching this language. American linguists also followed this way at the time of the Second World War. At first, the Americans were not interested in teaching 
foreign languages and the secondary school curriculum did not include them. The English language was enough as a means of communication in trade and other contacts with the world. The situation which arose during the Second World War changed this state of things. The US Army asked linguists to work out possibly quick methods of mastering foreign languages in a certain limited range. In this way American linguists started organizing scholarly work on the methodology of teaching foreign languages (Cf. W. G. Moulton Linguistics and Language Teaching in the United States. 1940-1960).

Their main aim was, and partly is, to work out an "intensive method" of teaching foreign languages. They even worked out half-year courses which made it possible to master a foreign language in a certain range. They turned attention to the interference of the native language on learning the structures of a foreign language. The basic rule and the sign-post of the American "linguistic method" was mastering the structures of a language through "sentence patterns". Frequent drills were to quicken the time of learning a foreign language. The works of Charles C. Fries and his disciples were the peak of this method. Great stress was put on language laboratories. An information and publication centre of the methodology of foreign language teaching ("Centre of Applied Linguistics"), created in Washington and directed by Prof. Fergusson, grew into a large institution.

As we have seen from the above consideration, linguistic problems were the basis of the new method worked out by American linguists, namely the new models of language structures were given. These models automatically influenced the method of teaching. At first, however, they neglected the psychology of teaching and general pedagogy. It is obvious that general pedagogy by itself could not afford to find new methods of teaching foreign languages. Its latest achievements, however, may be applied to the methodology of teaching foreign languages.

It is surprising that in the USA there is no special institute of the methodology of foreign language teaching. Publications on this subject are being done in centres of pure linguistics or in other institutes where foreign languages are taught, like universities, colleges, translators' schools, special schools of foreign languages. American theoretists do their scholarly work individually.

Classical structuralism gave us modern methods of teaching foreign languages. Recently we have seen a further development of structural-functional linguistics. Mathematical linguistics of different kinds has come out. It influences the methodology of teaching foreign languages, and it is certain that, for example, transformation grammar will exert its influence, too. Now we witness a new step in the development of mathematical linguistics or, perhaps in general, of structural-functional linguistics, namely cybernetical linguistics. It includes not only static language structures but also the whole communication process. Classical structural-functional linguistics was static. It treated language structures as static objects. Classical structuralists worked out the structures and their function by a written or spoken (tape-recorded) text. They were neither interested in the dynamics of these structures nor showed them and their functions in a communication act. They excluded "parole" from linguistic problems. But the language as a bilateral information body in a shape of graphic or aural transformation of a segment of the transformational chain is only a part of the mechanism, i.e. of a communication system of human beings. Language in itself is not only a store of written or taped texts but also primarily a store of matrices in the language centre of the brain. The characters of the inner and outer stores differ principally. The language centre of the brain does not store concrete sentences or texts but 
concrete morphemes. Sentences and texts are built on the basis of certain structural matrices (Cf. p. 132).

Until now structural linguistics as well as mathematical linguistics treated language structures as linear. Cybernetic linguistics treats the structures of communication process and the information body as feedback systems. It introduces to language analysis dynamic structures through the transformation of the body of language information and thus dynamizes the static structures of classical structuralism.

Arising cybernetical linguistics, characterised above, as a part of science about the communication process of human beings enters into the problems of the methodology of teaching foreign languages. Cybernetical linguistics as a set of systems of human language communication gave us the second "what" in foreign language teaching. Structural linguistics gave us the first "what" in a new shape, i.e. the language worked out as structures and their different functions. The second "what" may bel partly defined as the first "what" in the circulation of the communication process. Feedback is the characteristic feature of sets of communication, i.e. these sets have both transfer of information circuits and control and government circuits. The methodology of foreign language teaching has to give a thorough answer "how" to teach these two "whats". It has to search for the best way of building structural matrices of a foreign language, of building store matrices, of adopting transformation chains in speaking, i.e. transformation matrices with a change of material substance bearing meaning. All these problems are the subject of the modern methodology of foreign language teaching. The very construction of matrices and stores in language centres of the brain is the subject of linguistics while the methodology of foreign language teaching has to seek the best and quickest means of teaching a given foreign system of language communication. Cybernetical linguistics has to supply the methodology with full data about this system in its all transformational stages. The methodologist will need help from other related branches of science, e.g. psychology, physiology, general pedagogy and sociology. He will not, of course, do research in the above mentioned fields, but he will use their achievements from his point of view.

Classical structural-functional linguistics was divided into pure and applied. The applied cybernetical linguistics works out the concrete language material from the point of view of adopting this language. It will give us the second "what", i.e. whole concrete transformational sets of a speaking act based on corresponding store matrices (outer and inner). It will show in a great measure how to adopt the sets of speaking acts. The methodology based to a large extend on elements of general cybernetics will have to apply the achievements of the above mentioned related branches of science, i.e. psychology, physiology and general pedagogy. It will have to cooperate with electroacoustics since it starts using language laboratories. A clear distinction has to be made between applied cybernetical linguistics and the methodology of foreign language teaching. Applied linguistics works out the two "whats" as a subject of teaching while the methodology of teaching foreign languages with the help of related branches of science works on the problem "how" to adopt these two "whats". That makes the methodology undoubtedly an independent science. In the past it was usually one auxiliary branch of science that exerted a decisive influence on the methodology of foreign language teaching. In the times of classical structural linguistics it was linguistics and hence the methodology was included in applied linguistics. This situation has not changed even now. The methodology of foreign language teaching is still included in linguistic science. But it is a scientifically independent field although temporarily 
it may practically enter into the range of applied linguistics (of different types). It is, as we have mentioned, conditioned historically. Linguistics brought into methodology new trends of development. The necessity of cooperation between the methodology of foreign language teaching and related disciplines like psychology of teaching, physiology, etc. is obvious. Recently American scholars have come to this conclusion, too (Caroll, Lado and others).

The Institute of Applied Linguistics in Poznań will mainly do research work in the methodology of foreign language teaching, i.e. on "how" to adopt these two "whats". Since there are no institutes of pure and applied cybernetics this institute will have of necessity to work on these problems, too, but from the point of view of cybernetical linguistic theory. The static structures of classical structuralism will be looked upon from the point of view of their function in the communication process. Our stand is that it is the communication process which determines basically the structures treated by classical linguistics in a static way. It seems to us that structural statistic is fundamentally determined by the kinematic function of these structures in the act of communication.

The Institute of Applied Linguistics which is being set up now is only formally a new institution. Actually it has been a section of the Department of Germanic Linguistics for the last ten years. The time has come for it to be independent. The Institute has also taken over, as we have pointed out in another place, experimental courses held so far by the Department. Besides, the Institute of Applied Linguistics resumes research work on programmed teaching. In this field it will follow the theoretical assumption of cybernetics. It will also resume the task of constructing new language laboratories. The researches will go in two directions: 1. improving existing types of language laboratories with regard to technical equipment and 2 . working out adequate methods of laboratory teaching of foreign languages. It seems to us that it is just a beginning of working out modern methods of laboratory teaching. From the theoretical point of view existing laboratories with semiisolated boxes and ear-phones are not adequate for essential foundations of foreign language teaching in comparison with functioning of natural sets of oral communication acts. A laboratory corresponding to modern theories of states of sets of communication act should have loud-speakers and not ear-phones. Such a laboratory has to be, of course, properly damped. We assume that playing back and listening to his own taped voice by a learner and comparing it with teacher's voice is basicly wrong. This practice must lead to building a wrong matrix which produces sounds. All these are theoretical assumptions which have to be verified in practice. We shall be very glad to enter into contact with institutes or scholars working on these problems. Our stand is that the next step in the development of language laboratories is laboratories with loud-speakers. And the next will probably bring laboratories self-controlling the process of learning foreign languages. We shall try to bring research work in this direction in our Institute. Our article is to be published in IRAL (Ist der zweite Schaltungskreis ein Aufbaukreis?).

The Institute will pay special attention to teaching foreign languages in disadvantageous conditions, e.g. where there are a large number of pupils in one class. It is necessary to state objectively that in Europe the conditions are not advantageous in this respect. It would be very good, then, to test the means which make possible attainment of maximum effects of teaching in such conditions. Some experiments have to be made. 
The Institute will continue its research work on how to adopt and reproduce language structures without reflection. There will also be continued experiments to determine the method of teaching according to the age of learners. We have already made some experiments on this problem and we have obtained interesting results (Cf. Ludwik Zabrocki Experimental Courses of Foreign Language Teaching, Glottodidactica, p. 137). The Institute will work on other problems, like testing the degree of perception of structures and words in relation to time, the motivation of a lesson, etc. Special experiments will be devoted to the problems of intensive teaching and the rehabilitation of pronunciation. The latter is especially important because of the poor language knowledge which the secondary school gives to its pupils. There will be held comparative studies on applying various methods of teaching. Our opinion is that full elimination of grammar, i.e. meta-language, from the process of teaching is not proper. There is no time to automatize single structures. Therefore we do not think that grammar as a whole can be eliminated from the process of teaching. We assume that at the end of introducing structures grammatical rules should be given in a substitutional way. These rules should serve as a means of eliminating different structural chains. In our opinion it is the main aim of grammatical rules. We do not think it is good to build sentences and texts on the basis of grammatical rules or on generative grammar. And here some experiments have to be made to verify the theory. A special treatment of allomorphs, allophones and allographs seems to us to be a very important problem. We do not think that in the process of learning it would be proper to adopt all these subtleties through substitution. The economy of time does not allow us to do it. We have nothing to do with the Berlitz direct method and its contemporary followers of the pure linguistic methodology. These methods are good for tutors but not in condensed school teaching.

We shall be very glad if newly set up institutes and centres of applied linguistics take up some from the above mentioned problems. We are interested in exchange of results and experience. There are lots of such institutes in Western Europe, e.g. in Stockholm, Nancy, Besançon, Saint Clou, Sèvres, Heidelberg, and in the USSR, e.g. the institutes in Kiev and Moscow did interesting work on the methodology of teaching and programming. Our Institute has contacts with American centres, especially with Hunter College (Prof. Finocchiaro), Columbia University (Prof. Dykstra), California State College at Fullerton (Prof. Mathieu).

It is a fact that the methodology of teaching foreign languages is an independent branch of science which cannot be passed over in science. It wins more and more acknowledgement even in the university circles. The times of the $19^{\text {th }}$ and, partly, of the first half of the $20^{\text {th }}$ centuries belong to the past. Here and there the traditional scientific disciplines look unfriendly at the new science in university buildings lout the time works for the university rank of the methodology of foreign language teaching. Setting up the Institute of Applied Linguistics at the Adam Mickiewicz University in Poznań is a concrete sign of it. 